\title{
Biomechanical Parameterization of Front Handspring Vaults
}

\author{
Mario Jancosek' , Maria Danko ${ }^{1, *}$, Julia Ivankova' ${ }^{1}$, Andrej Somos' ${ }^{1}$ Jozef Zivcak ${ }^{1}$ \\ Technical University of Kosice, Letna 9, 04001 Kosice
}

\begin{abstract}
The motivation of the study is to demonstrate that by evaluating the training process using means to record and analyse the movement of individual body segments it is possible to effectively direct the training process to improve the position of individual body segments that are identified by the analysis as erroneous. By improving the position of individual body segments when performing a front handspring vault (FHV), thanks to targeted training focused on problematic segments, improvement in the posture of the whole body in the process of performing the vault will be achieved. The aim of the work is to contribute to the expansion of knowledge of explicit exercises applied in sports educology of the selected sports discipline. Based on the experimental decomposition of biomechanical parameterization. The study sample consists of ten young gymnasts (five boys $\left(\mathrm{n}_{\mathrm{bi}}=5\right)$ and five girls $\left(\mathrm{n}_{\mathrm{gi}}=5\right)$ ). Five boy gymnasts (average age $12.00 \pm 0.71 \mathrm{yrs}$; avg. body height $142 \pm 9.09 \mathrm{~cm}$; avg. BMl $17.47 \pm 0.78$ ) and five girl gymnasts (avg. age $11.40 \pm 0.89$ yrs; avg. body height $141 \pm 10.82 \mathrm{~cm}$; avg. BMl $17.47 \pm$ 1.01) took part in this study. Their task was to perform input and output FHVs $\left(n_{\| i}=10 ; n_{0 i}=10\right)$. We used the six-camera optoelectronic system for video-capturing motion analysis (SMART; BTS Bioengineering, Italy) and related technology to make clinical research in gymnastic training of the seven phases of the FHV. Thanks to motion analysis we recorded progress in changes of body symmetry after six weeks of gymnastic training of vaults.
\end{abstract}

Keywords: Biomechanics; Front Handspring Vault; Motion analysis; Kinograms; Gymnastics; Educology; Biomechanical Parameterization; Anthropometric Points.

\section{Introduction}

The vault is the basic all-around element of gymnastics $[1,2,3]$. It is based on a complex movement structure, as well as on intense physical effort realized within a short period of time. Fast position changes at each phase of the movement pattern require the gymnast to have excellent timing, aerial awareness and proper coordination of each involved body part $[2,3,4]$. The vaulting gymnast needs their motor skills to be highly developed; at the same time, exercising vaults adds to such development $[5,6]$. The vaulting movement pattern develops a gymnast's speed, agility, muscle power, courage and the will to compete $[1,7]$. The vaults have been evolving with time, effectively changing their movement structure, from simple vaults over natural obstacles to forms strictly defined by the relevant norms $[5,8,9,10]$. Each vault, regardless of its structure and level of complexity, includes elements such as the runup, hurdling onto a springboard, the first phase of the flight, the hands spring-off, the second phase of the flight and landing (see Figure 1) $[3,6,7]$.

A vault is a complex and short (not much more than 7 seconds on average) movement $[13,14,15,16]$. Board contacts are divided into the compression phase and the take-off phase. The first phase is characterized by extreme load and compression of a springboard while the second phase is characterized by the use of the elastic 


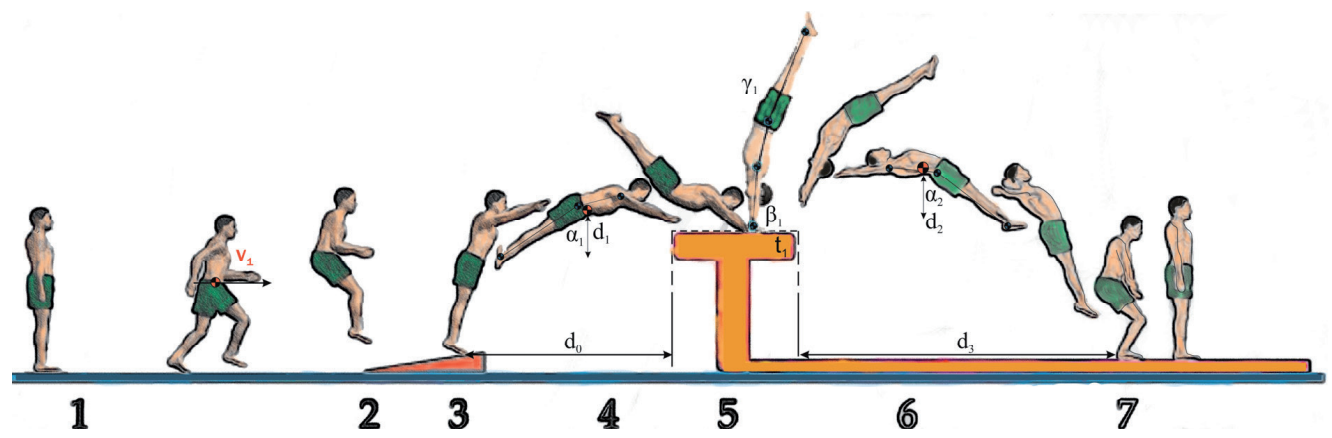

Figure 1: The Seven Phases of the Front Handspring Vault (1- Approach Run; 2- Take off; 3- Springboard contact; 4- First flight; 5Repulsion phase; 6- Post Flight; 7- Landing) [2, 3, 8].

Biomechanical indicators of front handspring vault $[2,10,11,12]$ :

$v_{1}$ - run-up speed, 3 m before the vault $\left(m \cdot s^{-1}\right)$

$d_{0}$ - spring distance before the vault $(\mathrm{cm})$

$d_{1}$ - height of the first phase of flight (cm)

$a_{1}$ - angle at the hip joint in the first phase of the flight $\left({ }^{\circ}\right)$

$\beta_{1}$ - upper limb absolute angle at hand contact with the vaulting table $\left({ }^{\circ}\right)$

$\gamma_{1}$-angle at the hip joint at hand contact with vaulting table $\left({ }^{\circ}\right)$

$t_{1}$ - time period when the hands touched the vault surface (s)

$d_{2}$ - height of the second phase of flight ( $(\mathrm{cm})$

$d_{1}-d_{2}$-difference in height between the 1st and the 2nd phase of flight (cm)

$a_{2}$-angle at the hip joint in the second phase of flight $\left({ }^{\circ}\right)$

$d_{3}$-landing distance $(\mathrm{cm})$

reaction of a springboard and maximal force of take-off muscles (all hip, knee and ankle extensors, trunk extensors and shoulder abductor). In order to gain sufficient angular momentum, the final takeoff force is always eccentric behind the body centre of gravity (BCG) (according to the direction of the jump) and in the direction of the jump $[14,16]$.

The duration of board contact is very short, about $0.12 \mathrm{~s}$, which is a very low value. As a rule, if a gymnast has a contact mainly with a front part of the foot on the board, the time is shorter while if the contact is mainly on the whole foot area, the board contact time is longer. This is also the reason why all pre-element vaults have a longer time of board support. The position of the feet on the board should be parallel, hip-width apart and BCG should be in the centre of the springboard according to the z-axis (left-right position) and toes should be placed $20 \mathrm{~cm}$ from the front edge of the springboard [14]. The problem of human interaction with a springboard is important as a human must adapt to the springboard elastic characteristics $[5,6$, $7,14]$. Each person has their own jump pattern and it is worth studying $[6,10,12,13,14,18]$. If any of the vaults elements is performed improperly, it has a negative impact on the final score.

\section{Methods}

The laboratory-based measurements were carried out in the gym (Popradska street, Kosice). At the beginning of the research, suitable probands were selected. Probands were chosen by experienced trainers. Participants started practicing gymnastics from the age of seven under the guidance of trainers with more than fifteen years of experience. Boys train five times a week for 2.5 hours and girls three times a week for 2 hours. The research sample is divided according to gender due to the anthropometric principles, movement abilities and due different schedule of training, and fitness training. The gymnasts, and their parents and coaches were acquainted with the goal and content of the research plan. Their task was to perform input and output front handspring vaults (FHV) for research measurement $\left(n_{1 i}=10 ; n_{0 i}=10\right)$. Between these measurements, they completed a six-week training program aimed at improving vaulting technique. The training program was consulted and audio-visually prepared with the national team coach Katarína Krekáňová. It includes seventeen preparatory exercises to improve the vaulting technique.

The study sample consists of ten young gymnasts (five boys (labelled persons $\mathrm{B}_{1}-\mathrm{B}_{5} ; \mathrm{n}_{\mathrm{bi}}=5$ ); and five girls (labelled persons $\left.G_{1}-G_{5} ; n_{g i}=5\right)$ ). Five boy gymnasts (average age $12.00 \pm 0.71 \mathrm{yrs}$; avg. body 
height $142 \pm 9.09 \mathrm{~cm}$; avg. body mass index 17.47 \pm 0.78 ) and five girl gymnasts (avg. age $11.40 \pm 0.89$ yrs; avg. body height $141 \pm 10.82 \mathrm{~cm}$; avg. body mass index $17.47 \pm 1.01$ ) took part in this study. They have been practising gymnastics since they were seven years old. The parents of all probands provided their informed consent with all of these measurements (inputs, outputs and six - week training program).

\section{Methods of obtaining and processing results}

The SMART system was used for measurement. It monitors the movement of the object by means of six cameras, which capture changes in the position of reflective marks attached to the body of probands. Video recording was used to obtain kinematic indicators of physical activity. This allows the use of a three-dimensional analysis of kinograms. The system obtains information based on the reflection of infrared light from a reflective coating applied to the surface of a mark that is attached to a moving object. Kinematic indicators of physical activity were obtained by video recording. All cameras were placed around the measured space to capture the required volume in which the measured activity was performed - a FHV. The method uses passive reflective markers that enable the recording of just a set of significant points distributed on the human body without recording the full-body details [19].

The SMART system can monitor the position, velocity, and acceleration of points in three axes of space individually. The MATLAB ${ }^{\oplus}$ software environment allows the user to approximate the missing points in motion trajectories, define the input parameters needed for further processing, calculate all required parameters, and display them either numerically or graphically. Subsequently, the data are exported for statistical processing and archiving. The workflow is shown in the Figure 2.

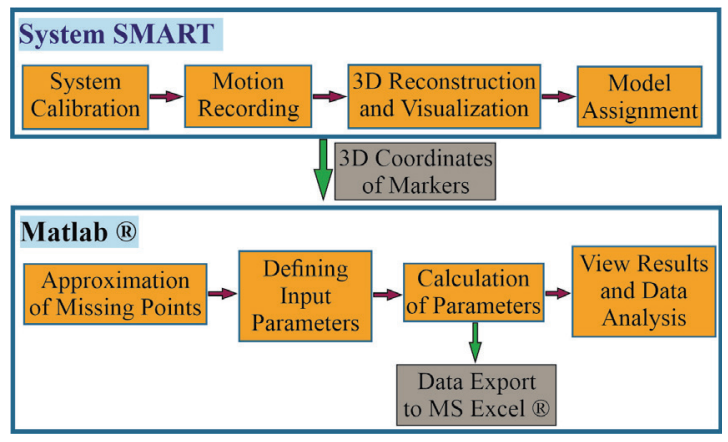

Figure 2: Block diagram of the SMART data processing.

Each proband had reflective markers attached at nineteen anthropological points. The chosen model was inspired by sets of markers used in the analysis of human movement around the world in research focused on gait analysis and adapted to the requirements of the study $[20,21,22,23]$.
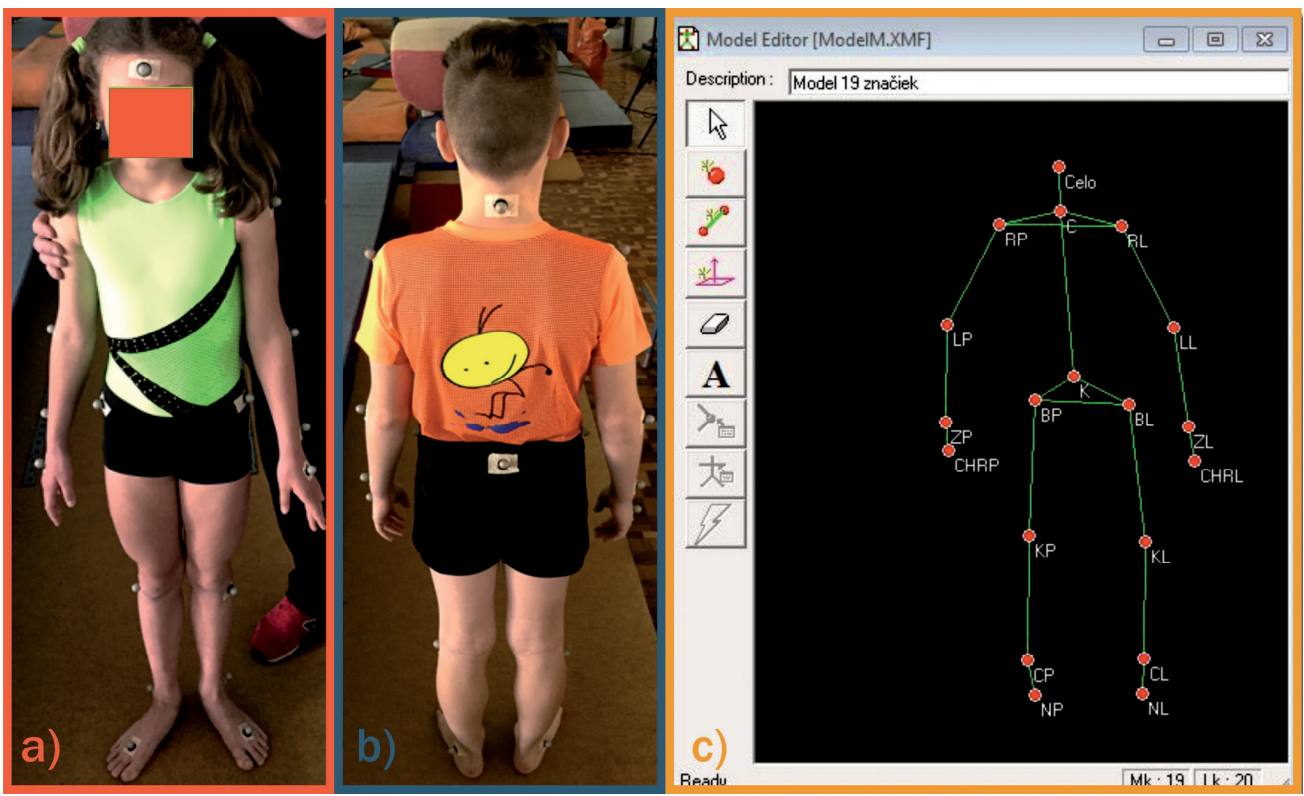

Figure 3: Positions of nineteen reflective markers on the human body. a) The anterior view b) The posterior view c) Model of markers placement on the human body in SMART software (in move). 
The placement of markers is shown in Figure 3 The motion analysis consists of input and output measurements of the seven phases of the FHV performed by each volunteer. The probands simulated regular vaulting conditions, and we recorded vault parameters for an FHV cycles of each individual. The research is focused on the detection of undesirable asymmetry of individual body segments in the sagittal, transverse, and frontal planes. Anthropometric tracking points were used to identify the main indicators of symmetry. We captured speed, trajectory, changes of body symmetry and angle changes using a six-camera optoelectronic system for motion analysis (SMART; BTS Bioengineering, Italy).

First, each gymnast from the study performed ten test input vaults $\left(n_{B i}=10 ; n_{G i}=10\right)$. After an analysis and consultation with trainers, the technically best performed FHVs were selected from these ten completed attempts. These best vaults performed by each gymnast were included in the input $\left(n_{1}=10\right)$ measurement. This was followed by a six-week training program aimed at improving technique. Seventeen scheduled and consulted exercises were practiced. After completing these trainings, an output measurement followed. It was performed under the same conditions as the input measurement $\left(\mathrm{n}_{\mathrm{Bi}}=10 ; \mathrm{n}_{\mathrm{Gi}}=10 ; \mathrm{n}_{\mathrm{Oi}}=10\right)$.

\section{Results and Discussion}

In conclusion, the angles of the hip joint in the second phase of the flight and when the hands touched the vault surface proved to be the most important indicators for the received score $[3,16$, 17, 18]. What needs to be highlighted herein is the fact that not all details of the performed vault are noticeable for the human eye. Therefore, each vault element in our study is analysed regarding its kinematic value; moreover, the level of a gymnast's physical preparation is estimated, which allows for improvement of the vault control and the process of teaching [2]. Physical parameters of vaults are generally known $[3,15,31,32,33]$. To identify the inaccuracy of performing jumps for individual body segments, it is necessary to use a recording device, in this case, the SMART optical measurement system, which allows to analyse the position and movements of individual parts of the body. Figure 4a) shows a record from the input measurement of the FHV of the first proband. It shows the greatest visible asymmetry in the hip joints in the frontal plane, which is quantitatively described in time $1.6 \mathrm{~s}$ with a difference of $7.3 \mathrm{~cm}$. At that time, the proband was performing the hands spring-off. During the output measurement, there was an improvement in the indicated phase of the jump (times are relative, it can by normalised, e.g. starting with take off or springboard contact). The measured asymmetry was $2.6 \mathrm{~cm}$ (Figure 4b).

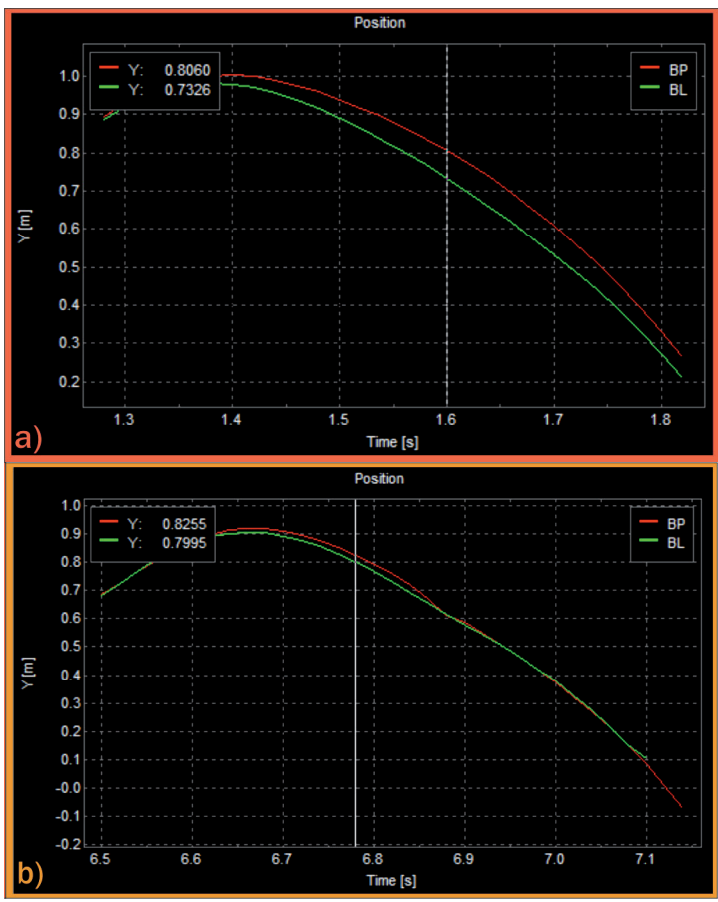

Figure 4: a) The input measurement of the first proband (labelled B1); b) The output measurement of the first proband (B1).

Probands were evaluated individually, as each of them has a different technique of performing the vault and other shortcomings in its implementation $[14,15,16]$. The comparison was made six weeks apart, during which the subjects underwent training as described above. The training was aimed at eliminating specific shortcomings that were identified during the initial measurements before the six-weeks training. From the first measurement (input), to the second measurement (output), the probands trained with a focus on improving the technique of FHV. When evaluating the records, the symmetry of the FHV between the right and the left side of the body was observed. By looking at the records, it was shown that the probands had 
problems keeping the body in symmetry during the FHV (see Fig.5 and Fig.6). In the frontal and transverse planes, the most frequently observed asymmetry of the hip joints was in the phase of the FHV, when the body should be in the plane above the reflecting surface. In poor attempts, the cause of right asymmetry of movement was between left and right sides of the person's body.

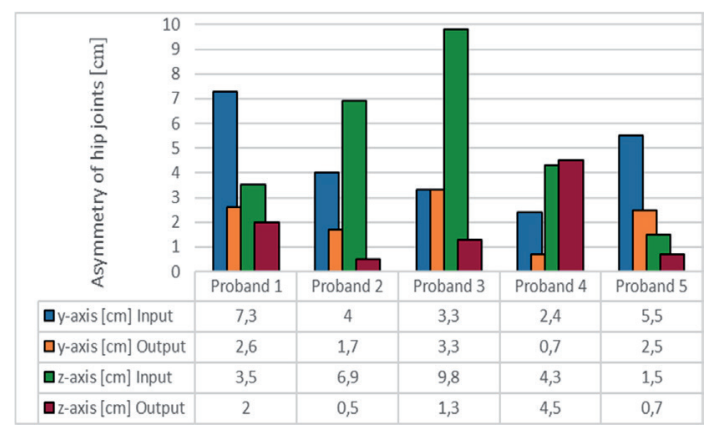

Figure 5: Measured hip asymmetry in boys in the transverse (y-axis) and medial planes (z-axis).

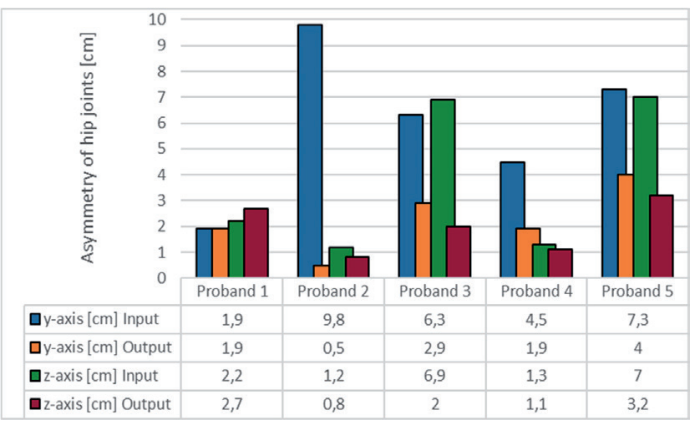

Figure 6: Measured hip asymmetry in girls in the transverse (y-axis) and medial planes (z-axis).

We focused on the evaluation of the symmetry of the probands' posture during the phase of touch and reflection from the vault table (the hands spring-off, repulsion phase; see Figure 1), when the body, especially the torso and legs, should be in a fixed symmetrical position. The jumps, described by the trainer as the best performed in a series of ten experimental FHVs during the input measurement $\left(n_{\| 1}=10\right)$ and also in the series of FHVs of the output measurement $\left(n_{\mathrm{Oi}}=10\right)$ after six weeks of training, were evaluated.

Based on the results, it is evident that targeted training focused on specific individual shortcomings in performing jumps, can improve the technique of performing jumps in six weeks (see Figure 5 and
Figure 6). One measurement consists of the seven phases of the FHV. Based on the biomechanical parameterization of the skeleton and individual body segments between input and output measurements, we can accept these hypotheses $(\mathrm{H})$ :

H1: The correct biomechanical parameterization of the vault style using motion algorithms will improve the locomotor position of the skeleton.

H2: Objective input parameters will determine the application of various motion algorithms.

H3: The chosen six-week explicit training program will have impact on the technique and performance of skip control.

\section{Conclusions}

In sports disciplines in which biomechanical parameterization of the movement structure is decisive in achieving a certain level of performance, there is also a growing need for their thorough analysis in order to improve the performance of gymnasts. Currently, the most important element in the vaulting technique is the extension and elevation of the flight parabola and the centre of gravity in the second part of the vault, after the arm spring off. Specialists pay significant attention to the run-up speed, the maximal force of the lower limbs, the angle of the take-off from the springboard and the orientation of anatomical segments and joint angles at hand contact with the vaulting table $[2,17,18]$. The human eye is not able to capture the movement of individual segments, especially in sports, where the positions of the segments rapidly change [19, 31, 32, 33], e.g. in-flight phase. With the exception of qualitative video feedback, the objective monitoring of the training, is not routinely part of gymnastics, with few known exceptions.

The 3D analysis of movement (System SMART) provides us with trajectories of movements of individual body segments, which allows thorough biomechanical analysis applicable to the methodology of teaching and training process not only in jumping gymnastics but also in sports where the interaction of proper function of individual body segments has a significant impact on the resulting movement and performance of a sports act. This statement also applies to its use in scientific research and training practice.

\section{Acknowledgments}

The work has been supported by research grant Application of 
Paradigms in Metrotomography, VEGA 1/0316/18, 01/2018 12/2020; APVV-19-0290,

\section{References and Notes}

1. Arkaev, L., Suchilin, G. (2004). How to Create Champions. Gymnastics. Oxford. UK. Meyer \& Meyer Sport. ISBN 978-184126-141-6.

2. Kochanowicz, A., Kochanowicz, K., Niespodziúski, B., Mieszkowski, J., Aschenbrenner, P., Bielec, G., \& SzarkEckardt, M. (2016). Maximal Power of the Lower Limbs of Youth Gymnasts and Biomechanical Indicators of the Forward Handspring Vault Versus the Sports Result. Journal of human kinetics, 53, 33-40. https://doi.org/10.1515/ hukin-2016-0008.

3. Atiković A. (2012). New Regression Models to Evaluate the Relationship between Biomechanics of Gymnastic Vault and Initial Vault Difficulty Values. Journal of human kinetics, 35, 119-126. https://doi.org/10.2478/v10078-012-0085-6.

4. Koperski A, Kochanowicz A, Słodkowski C. (2010). Gymnasts' special quickness-force abilities and the indicators of jump from a springboard. Balt J Health Phys Act, 2(2): 139-143.

5. Zaporožanov VA, Kochanowicz K, Kochanowicz A. (2014). Improvement of comprehensive assessment of specially trained childhood and adolescence gymnasts. Pedagog Psychol Med-biol Probl Phys Train Sports, 10: 3-7.

6. Ferkolj MA. (2010). Kinematic analysis of the handspring double salto forward tucked on a new style of vaulting table. Sci Gymnastics J, 1: 35-48.

7. Kerwin DG, Harwood MJ, Yeadon MR. (1993). Hand placement techniques in long horse vaulting. J Sport Sci, 11: 329-333.

8. Hall, E., Bishop, D. C., \& Gee, T. I. (2016). Effect of Plyometric Training on Handspring Vault Performance and Functional Power in Youth Female Gymnasts. PloS one, 11(2), e0148790. https://doi.org/10.1371/journal.pone.0148790.

9. Mkaouer, B., Jemni, M., Amara, S., Chaabène, H., \& Tabka, Z (2013). Kinematic and kinetic analysis of two gymnastics acrobatic series to performing the backward stretched somersault. Journal of human kinetics, 37, 17-26. https:// doi.org/10.2478/hukin-2013-0021.

10. Bradshaw E. (2004). Target-directed running in gymnastics: a preliminary exploration of vaulting. Gymnastics, Sports Biomechanics, 3:1, 125-144. DOl: 10.1080/14763140408522834.

11. Bradshaw E. (2010). Performance and health concepts in women's artistic gymnastics. XXVIII International Symposium of Biomechanics in Sports. Marquette, MI, USA, s. 51-55. ISSN 1999-4168.

12. Bradshaw E., Hume, P., Calton, M., Aisbett, B. (2009) Reliability of gymnastics vaulting feedback system. XXVII International
Symposium of biomechanics in sports limerick. Ireland.

13. Čuk, I., Karacsony, I. (2004). Vault, Methods, Ideas, Curiosities, History. Ljubljana: ŠTD Sangvinčki.

14. Čuk, I., Penič Samo, Sipej M. et al. (2011). Towards a smart springboard (case study). In: Science of Gymnastics Journal. Vol. 3 Issue 3: 29 - 42.

15. Hay, J. G. (1993). The biomechanics of sports techniques. 4th ed. Englewood Cliffs, N.J., United States, Prentice-Hall. 528p

16. Nelson, R. C. et al. (1985). Vaults performed by female Olympic gymnasts: A biomechanical profile. In: Sport. Biomechanics. Č. 1. s. 111.

17. Takei, Y. et al. (1992). A three-dimensional analysis of the men's compulsory vault performed at the 1992 Olympic games. In: Takei, Y. et al. International Journal of Sport Biomechanics, n. 6. P. $86-106$.

18. Takei, Y. (1989). Techniques Used by Elite Male Gymnasts Performing a Handspring Vault at the 1987 Pan American Games. In: International Journal of Sport Biomechanics, 5(1), 1-25.

19. Galajdova, A., Simsík, D., Rákay, R. (2016). An automated procedure for identification of a person using gait analysis. International Journal of Advanced Robotic Systems, 13.

20. Dolná, Z., Simsik, D., Galajdova, A. et al., (2010). An analysis of kinematic gait data variability. 4th International Symposium on Measurement, Analysis and Modelling of Human Functions 2010, ISHF 2010. 142-147.

21. Dolna. Z., Šimšík, D., Galajdová, A. (2009). A gait pattern classification based on human motion analysis usign SMART system. In: ESMAC London. P. 1.

22. Šimšík, D., Porada, V., Majernik, J. (2009). Marker free analysis of gait pattern applied in identification of individuals. In: 5 th European Academy of Forensic Science: book of abstracts : Glasgow, Scotland, UK. P. 57

23. Šimšík, D., Majerník, J. (2002). Gait analysis of free moving subjects. In: EMBEC 02. - Graz : Technischen Universität, 2002 P. 1210-1211. - ISBN 3901351620

24. Hudák, R., Penhaker, M., Majernik, J. (2012). Biomedical Engineering - Technical Applications in Medicine. 1. vyd. Rijeka : InTech. 420 p.. - ISBN 978-953-51-0733-0.

25. Dolná,Z., Šimšík, D., Galajdová, A. (2008). Human motion analysis and its application in sports and sport medicine. In: Lékař a technika. Vol. 38, no. 2 (2008), p. 152-155. - ISSN 0301-5491.

26. Majerník, J., Šimšík, D., Galajdová, A. (2005). Gait analysis in clinical praxis. In: Acta Mechanica Slovaca. Roč. 9, Č. 2-A YBERC (2005), s. 303-306. - ISSN 1335-2393.

27. Majerník, J., Živčák, J. (2015). Evaluation of postural stability using motion analysis techniques. In: Studies in Computational Intelligence vol. 606: Applications of Computational Intelligence in Biomedical Technology. - 
Cham: Springer, 2015 Vol. 606 (2015), p. 175-184. - ISBN 9783-319-19146-1 - ISSN 1860-949X.

28. Majernik, J., Šimšik, D.(2005). Marker-free analysis of human gait. In: EMBEC '05. - Prague : IFMBE, $4 \mathrm{p}$.

29. Šimšik, D., Majernik, J., Porada, V. (2008). Using of normative gait databases. In: Digital Forensic Forum Prague 2007. Karlovy Vary : Vysoká škola Karlovy Vary, 2008 P. 255-262. ISBN 9788025415368.

30. Živčák, J. et al. (2007). Biomechanics of Human Body I. [Biomechanika človeka I.] Presov: ManaCon.. ISBN 978-8089040-30-8.

31. Živčák, J. et al. (2007). Biomechanics of Human Body II. [Biomechanika človeka II.]. Prešov: ManaCon.ISBN 978-8089040-31-5.

32. Živčák, J., Knežo, D. (2008). Biomechanics of Momentum [Biomechanika hybnosti]. Prešov: Grafotlač. Prvé vydanie. ISBN 978-80-8068-608-6.

33. Živčák, J., et al., (2012). Goniometry of the Human Locomotor System [Goniometria pohybovej sústavy človeka]. Prešov: Grafotlač. 288s. ISBN 978-80-553-1273-6.

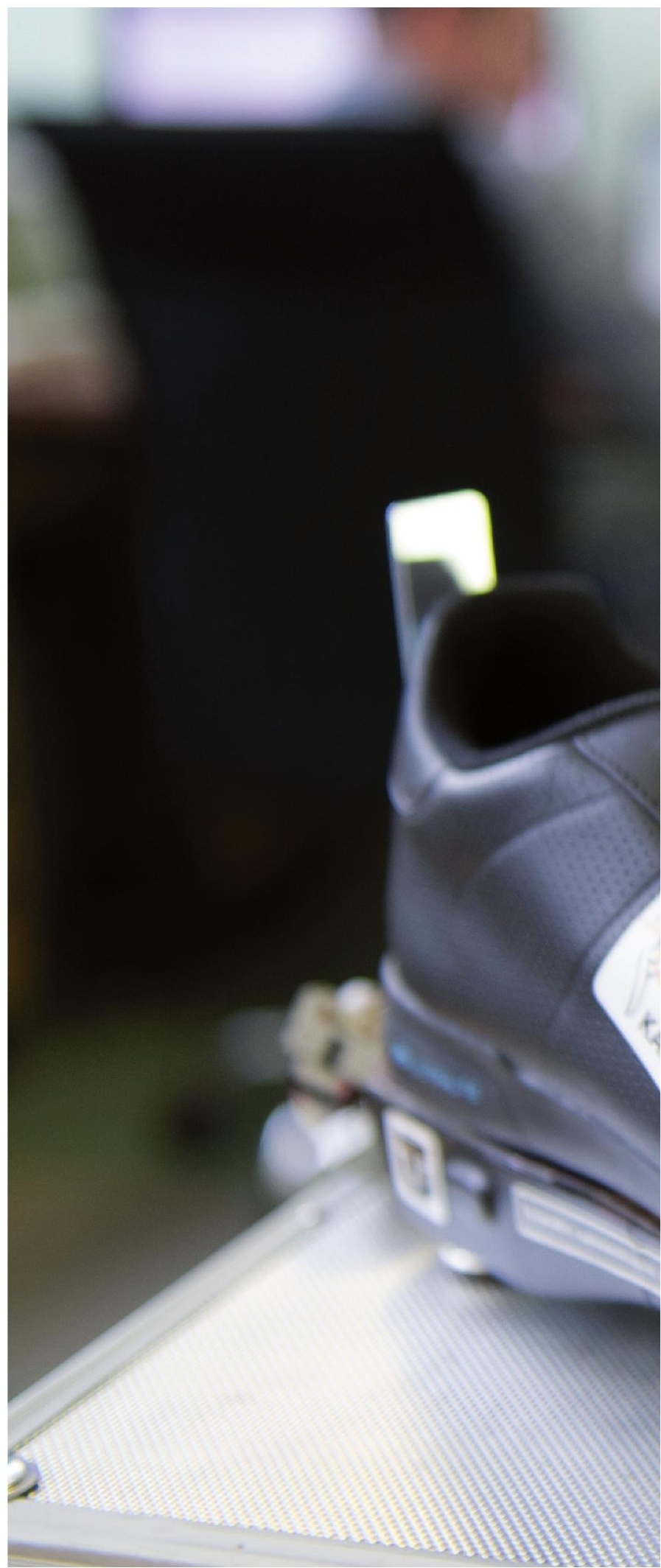

